\title{
Juego de roles y reportajes audiovisuales para el desarrollo de competencias transversales en Aprendizaje Basado en Proyectos
}

\author{
Sentieri-Omarrementería, Carla ${ }^{a}$; Martínez-Ventura, Jordi ${ }^{\mathbf{b}}$; de Miguel-Pastor, María ${ }^{\mathrm{c}}$ \\ Departamento de Proyectos Arquitectónicos, Universitat Politècnica de València \\ acarsenom@pra.upv.es, bjormarv4@doctor.upv.es, ${ }^{c}$ mamipas@doctor.upv.es \\ ${ }^{\text {bc }}$ Desarrollado bajo el programa de ayudas de Formación de Profesorado Universitario del Ministerio \\ de Educación, Cultura y Deporte del Gobierno de España
}

\begin{abstract}
Resumen
El plan Bolonia ha supuesto un cambio de paradigma centrado en un aprendizaje basado en competencias. En este contexto, las competencias transversales son fundamentales y un valor añadido para los egresados a la hora de integrarse en el mercado laboral. La Universitat Politècnica de València inició un proyecto para trabajar trece de ellas: Proyecto de competencias transversales (http://www.upv.es/contenidos/COMPTRAN/). Como consecuencia de esta iniciativa, en distintos cursos-desde segundo hasta quinto- del Grado en Fundamentos de la Arquitectura, en la escuela de arquitectura de esta universidad, las asignaturas basadas en el desarrollo de proyectos arquitectónicos iniciaron varias experiencias educativas para trabajarlas y evaluarlas.
\end{abstract}

Este trabajo se enmarca en un repositorio online de buenas prácticas en el ámbito de la arquitectura que recopila un conjunto de casos de Aprendizaje Basado en Proyectos, describiendo las diferentes actividades educativas llevadas a cabo, y cómo éstas desarrollan y evalúan las competencias transversales seleccionadas: trabajo en grupo y liderazgo, comunicación efectiva oral y gráfica, planificación y gestión del tiempo, pensamiento crítico, conocimiento de problemas contemporáneos, responsabilidad ética, medioambiental y profesional e instrumental especifica; con el objetivo de motivar, estimular y ofrecer herramientas a cualquier profesor que trabaje mediante proyectos y quiera mejorar las competencias transversales de los alumnos.

Como resultado, se presentan las actividades llevadas a cabo durante el desarrollo de un proyecto de alojamiento colectivo -cohousing- para personas de la tercera edad. Se analiza el trabajo realizado y, en particular, una actividad colaborativa donde los estudiantes participaron en un juego de inmersión mediante la interpretación de roles de personas de la tercera edad 
Juego de roles y reportajes audiovisuales para el desarrollo de competencias transversales en Aprendizaje Basado en Proyectos

con alguna limitación física. Concretamente se desarrollan las competencias de comunicación oral y gráfica y de conocimiento de problemas contemporáneos relacionados con esta temática. Asimismo, se presentan los vídeos de los reportajes realizados por los alumnos como resultado de la actividad.

Palabras clave: Metodología, vídeo, diseño, pensamiento creativo, proyectos arquitectónicos.

\section{Introducción}

En la actualidad, las universidades europeas giran en torno a un aprendizaje basado en competencias como consecuencia de la implantación de los planes de estudio promovidos por el Espacio Europeo de Educación Superior (EEES) a través del proceso Bolonia. El objetivo fundamental de estos planes es dotar a los alumnos de un conjunto de habilidades que les capacite en aquellas competencias demandadas por el mundo empresarial, con el objeto de facilitar y acelerar a los egresados su integración plena en el mercado laboral.

Podemos encontrar distintas formas de clasificar las competencias (Rodríguez, 2007) y sus implicaciones en el aprendizaje (Riesco, 2008), así como distinción entre competencias académicas, profesionales y laborales (Charria et al., 2011). Sin embargo, el proyecto Tuning $^{1}$ se ha convertido en un referente fundamental en la clasificación de las competencias en el marco del EEES, estableciendo dos tipos: las Competencias Específicas (CEs) y las Competencias Transversales (CTs). El trabajo que se presenta en este artículo se centra en las CTs en el ámbito de la arquitectura, que son aquellas que definen un perfil que no se asocia a ningún área de conocimiento específico, y son transferibles a una amplia variedad de contextos laborales (Ej. trabajar en equipo, creatividad, etc.).

La asignatura de Proyectos en Arquitectura ofrece un contexto idóneo y una oportunidad para trabajar y evaluar estas competencias mediante la introducción en el aula de Actividades Educativas (AEs) innovadoras que permitan el desarrollo y la correspondiente evaluación de las CTs. Y es bajo estas condiciones donde el juego de rol permite generar un contexto para obtener información sobre "saber ser". De acuerdo con Krain \& Lantis (2006: 396) citado por Gaete-Quezada (2011: 291), los ejercicios de simulación, como el juego de roles, "mejoran la experiencia educativa ya que promueven el pensamiento crítico y las habilidades analíticas, ofreciendo a los estudiantes un nivel más profundo en la dinámica de

\footnotetext{
${ }^{1}$ Proyecto "Tuning - Sintonizar las estructuras educativas de Europa": http://www.eees.es/es/eees-estructuraseducativas-europeas
} 
intercambio político, el fomento de las competencias de comunicación oral y escrita y el fomento de la confianza en los estudiantes".

$\mathrm{Y}$ junto al juego de roles, se ha utilizado la realización de videos cortos, de aproximadamente dos a tres minutos de duración, en que se combinan imágenes estáticas y/o en movimiento, música, efectos de sonido, etc., con una narración creada y grabada por los alumnos, con el objetivo de comunicar un mensaje que incluyese su punto de vista sobre la temática del curso y las conclusiones de su experiencia en el juego de roles. Como cita Rosales (2014), las historias y los relatos representan uno de los medios más antiguos en la transmisión del conocimiento (Duveskog et al., 2012). El relato digital, que es el empleado en la asignatura de proyectos, es la versión tecnológica del antiguo arte de contar historias. En él se combinan elementos multimedia como imágenes, sonido, música y otros para comunicar un mensaje (Xu et al., 2011). Y, aunque se han usado en distintos ambientes desde hace más de treinta años, su inclusión en el campo educativo es relativamente reciente (Duveskog et al., 2012; Rosenthal Tolisano, 2009; Robin, 2006).

Dado que proyectar en arquitectura es una actividad creativa muy compleja (Cosme, 2008), el proyectista debe poseer tal diversidad de conocimientos y técnicas para desarrollarla que hacen que el aprendizaje del diseño de proyectos sea una de las disciplinas más arduas con las que se tiene que enfrentar un estudiante de arquitectura (Sentieri et al., 2009).

Las asignaturas de proyectos en la escuela de arquitectura de la Universitat Politècnica de València (UPV), se encargan de acompañar en este aprendizaje, que se consigue mediante dominio del conocimiento, saber hacer (aplicación) y saber ser (convencer). La metodología es el Aprendizaje Basado en Proyectos (ABP) y el desarrollo de la asignatura se concibe mediante la realización de proyectos arquitectónicos de forma individual o grupal. Este ABP se puede organizar como un conjunto de actividades por etapas para la consecución de un objetivo -el desarrollo de un proyecto arquitectónico- $\mathrm{y}$, parece idóneo utilizar y rediseñar sus actividades también para el desarrollo de las CTs, dado que durante el proceso los alumnos tienen que diseñar y proyectar un espacio mediante un instrumental específico con programas de cálculo y diseño; donde se trabaja en grupo y se requiere de liderazgo para orientar los análisis o las propuestas colaborativas; se exponen en público los resultados; y se desarrolla el pensamiento crítico con la participación de los alumnos con comentarios y revisiones de los ejercicios, todo ello, dentro de un plazo determinado y bien planificado. Teniendo en cuenta que el arquitecto presta un servicio a la sociedad, además, este debe conocer los problemas contemporáneos y desarrollar una actitud ética, medioambiental y profesional. Por todo ello, el presente artículo aborda las metodologías de trabajo y evaluación para desarrollar competencias transversales en arquitectura, y en $\mathrm{ABP}$, entre las que destacan el juego de roles y la creación de videos. 
Juego de roles y reportajes audiovisuales para el desarrollo de competencias transversales en Aprendizaje Basado en Proyectos

\section{Contexto}

Este trabajo se enmarca en el contexto del desarrollo de las CTs en los alumnos que cursan titulaciones relacionadas con el área de arquitectura en la UPV, dentro del marco del Proyecto de competencias transversales de esta universidad y en continuidad con trabajos previos desarrollados en el curso 2016/17 (Sentieri et al., 2018).

La puesta en marcha del proyecto de CTs de la UPV supuso en el curso 2015/16 que todos los profesores responsables de cada asignatura diseñasen, integrasen y describiesen en las guías docentes actividades específicas para el desarrollo y evaluación de las CTs, generalmente mediante el uso y aplicación de metodologías activas de aprendizaje, dada su idoneidad, y además en el caso de las asignaturas "punto de control" también el diseño e integración de actividades de evaluación para recoger las evidencias que permitieran valorar de forma cuantitativa y/o cualitativa los indicadores que evalúan el grado de alcance de las CTs. Para facilitar la tarea de evaluación, la UPV dentro del proyecto de CTs ha desarrollado un conjunto de rúbricas que definen de forma genérica los ítems a valorar en cada competencia según el nivel a evaluar y que cada profesor responsable de las asignaturas "puntos de control" debe adaptar a su asignatura.

\section{Objetivo}

El grupo de innovación educativa (EICE) IcaPA (Innovación y Calidad en el Proyecto Arquitectónico), cuyos esfuerzos se han centrado principalmente en adaptar las asignaturas de Proyectos al EEES (Domingo et al., 2011) y crear herramientas en la nube para el desarrollo y evaluación de competencias transversales en diferentes ámbitos (Segrelles et al., 2015, 2016), entre los que se encuentra el área de arquitectura (Segrelles et al., 2017), inició un trabajo previo -en varias asignaturas del Grado en Fundamentos de la Arquitectura (GFA) de la UPV- trabajando distintas competencias con el objetivo de orientar una correcta implementación en el área de arquitectura o de la ingeniería para ofrecer al cuerpo docente de la UPV un repositorio de guías de buenas prácticas en la nube que faciliten el desarrollo y evaluación de CTs de una forma metódica, reproducible y trasladable a otras disciplinas (Sentieri et al., 2018) incorporando en el curso 2017/18 nuevas actividades mediante el juego de roles y la realización de videos cortos para mejorar la formación de los alumnos en competencias transversales. 


\section{Metodología}

Las asignaturas de proyectos arquitectónicos tienen como objetivo formar al alumno y capacitarlo para desarrollar proyectos arquitectónicos, con diferentes grados de complejidad en cada curso, mediante la realización de un proyecto de edificación.

La realización de un proyecto/anteproyecto arquitectónico consiste en el diseño de un edificio con un programa concreto en un lugar determinado, con el desarrollo de planos y memorias que permitan su trasmisión a otros agentes para que lo puedan ejecutar. Este trabajo, que es una de las tareas a las que se dedica mayoritariamente el arquitecto, se desarrolla dentro de las aulas de la manera más real posible para que el alumno comience a desarrollar las competencias que necesitará en su ejercicio profesional.

En continuidad con el trabajo de recopilación de buenas prácticas (Sentieri et al., 2018), el proceso desarrollado durante el curso 2017/18 se estructura de la misma forma, estableciendo categorías en función de la fase del proyecto que trabajan: análisis del lugar, análisis del programa/usuario, análisis de referentes, primeras ideas o planteamientos y propuesta final, pero integrando el juego de roles y la creación de videos para introducir al alumno en el problema que tiene que resolver.

El juego de rol en un entorno presencial se suele entender como una interpretación en la que los estudiantes adoptan algún personaje o rol -en este caso el de persona de la tercera edad- y defienden una postura (Noguera, 2015) y es una técnica de enseñanza-aprendizaje mediante la que, de un modo colaborativo, los alumnos aprenden jugando y experimentando bajo la orientación del profesor, en una situación de simulación que nunca logra reproducir de forma completa las circunstancias reales, pero que sí permite aproximarse a ella; por lo que constituyen un buen sistema para facilitar los aprendizajes orientados a la comprensión (Castelló, 2007). Estos juegos pueden ayudar a desarrollar habilidades psicológicas, cognitivas, físicas y/o sociales, por lo que se han ido incorporando poco a poco en las aulas como complementos curriculares y mediadores del proceso de aprendizaje (Valiño, 2002). Además, esta técnica es válida para ayudar a entender un problema y desarrollar la empatía, la posibilidad de ponernos y comprender la situación de los demás (De Urbina, 2010).

Así pues, dada la temática del curso en torno a la tercera edad, el vídeo o relato digital, se ha utilizado para mostrar la percepción de los alumnos sobre el tema en particular (Robin, 2006) y sus conclusiones a partir del juego de roles. El relato digital ofrece una plataforma neutra en la que los estudiantes se sienten seguros para compartir sus historias, ofrece variedad de formas, aumenta su motivación, mejora la creatividad, imaginación y concentración, y puede ser almacenado para próximas generaciones (Duveskog et al., 2012). 
Juego de roles y reportajes audiovisuales para el desarrollo de competencias transversales en Aprendizaje Basado en Proyectos

\section{Resultados}

\subsection{Ejemplo de AEs en un proceso ABP}

El momento actual y los tiempos que vienen apuntan a un cambio global en el modelo de desarrollo, de modo que se pueda asegurar un futuro sostenible para la vida en el planeta a través de la armonización del crecimiento económico, la inclusión social y la protección ambiental. Para ello, la Organización de las Naciones Unidas ha liderado el desarrollo de la Agenda 2030 y definido 17 Objetivos de Desarrollo Sostenible (ODS), proponiendo un mundo para el año 2030 en torno a cinco elementos fundamentales: las personas, el planeta, la prosperidad, la paz y las alianzas.

En su planteamiento de perspectiva multidimensional, este el curso 2017/18 el Taller $4^{2}$ ha centrado su atención, a través del tema transversal Palabras mayores, en uno de los retos más importantes que se plantean para el futuro. Si bien en los años 80 las personas mayores de 60 años suponían alrededor de un $8 \%$ de la población mundial, en la actualidad esta cifra ha aumentado hasta el $10 \%$ y se prevé que supere el $20 \%$ en 2050 , alcanzando el $33 \%$ de los habitantes en los países desarrollados. De este modo, se hace necesario que la arquitectura atienda, con mayor dedicación que nunca, sus necesidades.

En este ejemplo se desarrolla un proyecto de alojamiento colectivo para la tercera edad enumerando las AEs desarrolladas junto con las competencias transversales que se trabajan (Tabla 1), y posteriormente, mostrando la apariencia de estas en el repositorio.

Tabla 1. Competencias Transversales por Actividad Educativa

\begin{tabular}{|c|c|c|}
\hline Actividades Educativas & Competencias Transversales & \\
\hline 1. Juego de roles y vídeo & $\begin{array}{l}\text {-Trabajo en grupo y liderazgo. } \\
\text {-Comunicación efectiva oral y gráfica. } \\
\text {-Planificación y gestión del tiempo. } \\
\text {-Pensamiento crítico. }\end{array}$ & $\begin{array}{l}\text {-Conocimiento de problemas contemporáneos. } \\
\text {-Responsabilidad ética, medioambiental y profesional. } \\
\text {-Instrumental específica. }\end{array}$ \\
\hline $\begin{array}{l}\text { 2. Análisis del lugar } \\
\text { 3. Análisis del programa } \\
\text { 4. Análisis referentes } \\
\quad \text { alojamiento }\end{array}$ & $\begin{array}{l}\text {-Comunicación efectiva oral y gráfica. } \\
\text {-Planificación y gestión del tiempo. } \\
\text {-Pensamiento crítico. }\end{array}$ & $\begin{array}{l}\text {-Conocimiento de problemas contemporáneos. } \\
\text {-Responsabilidad ética, medioambiental y profesional. } \\
\text {-Instrumental específica. }\end{array}$ \\
\hline $\begin{array}{l}\text { 5. Primeros planteamientos y } \\
\text { desarrollo } \\
\text { 6. Presentación final }\end{array}$ & $\begin{array}{l}\text {-Diseño y proyecto. } \\
\text {-Comunicación efectiva oral y gráfica. } \\
\text {-Planificación y gestión del tiempo. } \\
\text {-Pensamiento crítico. }\end{array}$ & $\begin{array}{l}\text {-Conocimiento de problemas contemporáneos. } \\
\text {-Responsabilidad ética medioambiental y profesional. } \\
\text {-Instrumental específica. }\end{array}$ \\
\hline
\end{tabular}

\footnotetext{
${ }^{2}$ Unidad Docente Taller 4, Departamento de Proyectos Arquitectónicos, Universitat Politècnica de València
} 


\subsection{Juego de roles y vídeos. Tomando conciencia de una realidad.}

Para el desarrollo del juego de roles se organiza un almuerzo para todos los alumnos, habiendo creado previamente grupos de 3 para realizar la actividad. Cada grupo debe traer algo al almuerzo (papas, aceitunas, vasos y platos de plástico, etc.) junto con varios objetos (medias, celo, gafas oscuras, palo, flotador, manguitos, etc.). Durante el almuerzo, los alumnos tienen que participar con alguna limitación física (con una pierna atada, medias en las manos, dificultad de visión...) de tal modo que se aproximen a una experiencia física más cercana a la tercera edad (Fig. 1).

En primer lugar, un alumno por grupo tiene que colocarse los materiales que han traído para experimentar la dificultad en los movimientos. Mientras tanto, sus compañeros tienen que ayudarle, tomar notas, hacer fotos y grabar en vídeo las dificultades que observan.

En una segunda etapa, finalizado el almuerzo, los alumnos deben ir a sus casas o pasear por la universidad para comprobar nuevas dificultades y tomar notas sobre éstas.

Por último, con el material recogido y con reflexiones complementarias sobre la tercera edad (entrevistas, documentación, lecturas, etc.), los grupos de alumnos elaboran un vídeo, evaluado mediante rúbricas empleadas para la valoración de CTs -disponibles en el repositorio online $e^{3}$ que se comparte en Google Drive y se expone en el aula al resto de compañeros, que realizan una votación para elegir el mejor y justificarlo (Fig. 2).

Algunos de los resultados de estos vídeos son accesibles desde el mismo repositorio de buenas prácticas ${ }^{3}$.

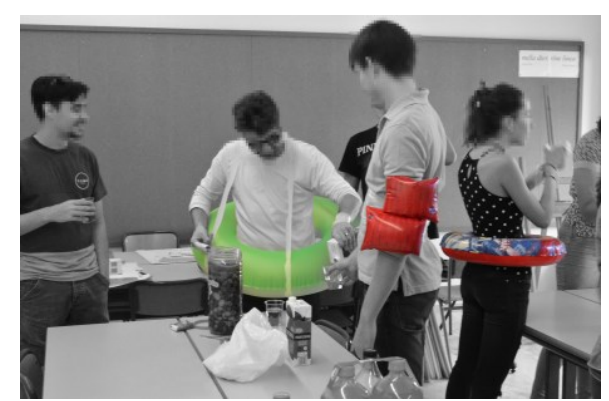

Fig. 1 Desarrollo del almuerzo. Proyectos 2. Taller 4. ETSA UPV. Curso 2017-18

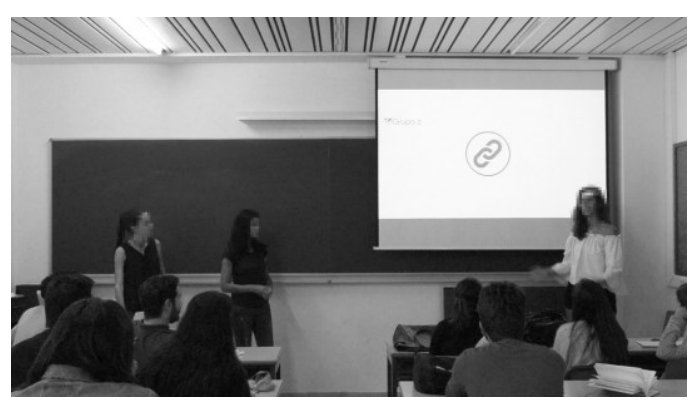

Fig. 2 Exposición del video en el aula. Proyectos 2. Taller 4. ETSA UPV. Curso 2017/18

Tras esta primera actividad de inmersión en el tema, el alumnado desarrolla el proyecto a través de una serie de actividades.

\footnotetext{
${ }^{3}$ https://competenciastransversalesupv.wordpress.com/2018/05/30/juego-de-roles/
} 
Juego de roles y reportajes audiovisuales para el desarrollo de competencias transversales en Aprendizaje Basado en Proyectos

\subsection{Análisis del lugar.}

Consiste en un análisis del lugar desde el punto de vista geográfico, histórico, sociocultural y urbanístico/arquitectónico con la realización de un mapa síntesis tomando como referencia un mapa del libro Mapas: Explorando el mundo, de Phaidon, para trabajar la comunicación gráfica.

\subsection{Análisis del programa/usuario.}

Desde el punto de vista de los usuarios.

\subsection{Análisis de proyectos de vivienda y cohousing.}

Desde la funcionalidad, la estructura, la construcción y la materialidad.

\subsection{Primeros planteamientos y desarrollo.}

Propuesta de las primeras ideas o aproximaciones a la solución del proyecto.

\subsection{Presentación final y entrega.}

En la fecha indicada para la entrega final, el alumno presenta toda la documentación correspondiente al desarrollo del proyecto con planos y memoria, una maqueta del proyecto y un panel resumen en formato DIN A1 con la información más relevante.

\subsection{Incorporación al repositorio.}

Todas estas actividades se recogen en un repositorio ${ }^{4}$ (Sentieri et al., 2018) en el que, en la primera pantalla de presentación, se puede hacer una selección de AEs por competencia transversal trabajada o por tipo de AE. Cada AE se describe de forma precisa, escueta, a modo de receta con los siguientes apartados: datos, diseño de la actividad describiendo los ingredientes o necesidades de partida, la elaboración, el proceso y la evaluación junto con las rúbricas empleadas para la valoración de las competencias transversales.

\section{Conclusiones}

Como se pudo comprobar durante el curso, el juego de roles y la realización de los videos, permitió al alumnado profundizar en las condiciones del usuario para el que tenían que resolver el proyecto y motivó su interés en ello. Durante las sesiones siguientes, algún alumno trajo un corto sobre la memoria en la tercera edad, se adjuntaron reflexiones personales sobre cómo se imaginaban en esa situación y muchos de ellos conversaron con sus abuelos y visitaron algún alojamiento para la tercera edad próximo a su lugar de residencia. Un cuestionario realizado online, permitió recoger sus experiencias y confirmar que el juego de roles les había ayudado a tomar conciencia del problema.

\footnotetext{
${ }^{4}$ https://competenciastransversalesupv.wordpress.com/2018/05/30/juego-de-roles/
} 
Para mejorar el trabajo de las competencias se debe establecer un protocolo más específico y evaluar cada una de ellas en momentos denominados "puntos de control", pero sin perder de vista que el objetivo es el formativo y no el "clasificatorio". El tiempo que conlleva registrar todos estos datos puede hacer que se pierda un tiempo muy valioso para nuevas revisiones ofeedback.

El repositorio generado permite la utilización de las guías por parte de cualquier profesor que trabaje CTs a través de ABP. El hecho de describir con imágenes el contexto, el desarrollo y la evaluación permite que cada profesor se plantee nuevas actividades vinculadas con su materia específica, aprovechando las rúbricas de las que se disponen y la experiencia en tiempos para las planificaciones. Es fácilmente sostenible porque solo requiere tomar datos de las actividades que se van realizando, incluso se podría plantear como trabajo futuro algún tipo de $b \log / w e b$ de carácter participativo donde cada uno subiera o volcara su información, de tal modo que se generase una red de buenas prácticas.

Además, el propio repositorio, permite embeber todo el material en la propia plataforma, posibilitando la disponibilidad en abierto de todos los recursos que se requieren para la puesta en marcha de las diferentes actividades. Si bien es cierto, queda introducir los recursos en todas las guías publicadas, dado que actualmente solo se proporciona para el ámbito de trabajos cooperativos arquitectónicos (Segrelles et al., 2017).

\section{Agradecimientos}

Los autores agradecen la financiación recibida del Vicerrectorado de Estudios, Calidad y Acreditación de la Universitat Politècnica de València para desarrollar el Proyecto de Innovación y Mejora Educativa (PIME) Repositorio en la nube de buenas prácticas para el desarrollo de competencias transversales mediante aprendizaje basado en proyectos arquitectónicos.

\section{Referencias}

Charria Ortiz, V. H., Sarsosa Prowesk, K. V., Uribe Rodríguez, A. F., López Lesmes, C. N., Arenas Ortiz, F. (2011). Definición y clasificación teórica de las competencias académicas, profesionales y laborales: Las competencias del psicólogo en Colombia. Psicología desde el Caribe, 28, 133165.

Rodríguez Esteban, A. (2007). Las competencias en el Espacio Europeo de Educación Superior: tipologías. Humanismo y Trabajo Social, 6, 139-153.

Riesco González, M. (2008). El enfoque por competencias en el EEES y sus implicaciones en la enseñanza y el aprendizaje. Tendencias Pedagógicas, 13, 79-105.

Gaete-Quezada, R. A. (2011). El juego de roles como estrategia de evaluación de aprendizajes universitarios. Educación y educadores, 14 (2), 289-307.

Krain, M., Lantis, J. S. (2006). Building Knowledge? Evaluating the Effectiveness of the Global Problems Summit Simulation. International Studies Perspective Journal, 7 (4), 395-407. 
Juego de roles y reportajes audiovisuales para el desarrollo de competencias transversales en Aprendizaje Basado en Proyectos

Rosales, M. H. (2014). Del paradigma cognitivo al saber hacer en la formación por competencias. Revista UNASAM, 1 (1), 211-225.

Cosme, A. M. (2008). El proyecto de arquitectura: concepto, proceso y representación. Barcelona: Editorial Reverte.

Sentieri, C., Castellanos, R., López, R. (2009). El aprendizaje de proyectos centrado en la indagacióncomparación. In Actas III Jornadas Internacionales sobre U.P.M sobre Innovación Educativa y Convergencia Europea (INECE'09). Madrid.

Sentieri, C., Segrelles, D. (2018) Repositorio en la nube de Buenas Prácticas para el Desarrollo de Competencias Transversales mediante un Aprendizaje Basado en Proyectos Arquitectónicos. In IV Congreso Internacional sobre Aprendizaje, Innovación y Competitividad (CINAIC 2017) (pp. 86-91). Zaragoza.

Noguera Fructuoso, I. (2015). Rediseño de dos asignaturas incorporando el juego de rol y Twitter para fomentar la motivación de los estudiantes. @ tic. revista d'innovació educativa, (14), 31-40.

Valiño, G. (2002). La relación juego y escuela: Aportes teóricos para su comprensión y promoción. Revista Conceptos, 77 (2).

Castelló, T. (2007). El disseny d'activitats facilitadores de l'aprenentatge. Girona: Institut de Ciències de lEducació Josep-Pallach de la UdG.

De Urbina Criado, M. O., Medina Salgado, S., De La Calle Durán, C. (2010). Herramientas para el aprendizaje colaborativo: una aplicación práctica del juego de rol. Teoría de la Educación. Educación y Cultura en la Sociedad de la Información, 11 (3), 277-300.

Duveskog, M., Tendre, M., Isalas, C., Sutinen, E. (2012). Life Planning by Digital Storytelling in a Primary School in Rural Tanzania. Educational Technology \& Society, 15(4), 225-237.

Xu, Y.,Park, H., \& Baek, Y. (2011), A New Approach Toward Digital Storytelling: An Activity Focused on Writing Self-efficacy in a Virtual Learning Environment. Educational Technology \& Society, 14(4), 181-191.

Rosenthal Tolisano, S. (2009). How-to-guide: digital Storytelling, Tools for Educators. Retrieved from http://langwitches.org/blog/wp-content/uploads/2009/12/Digital-Storytelling-Guide-bySilvia-Rosenthal-Tolisano.pdf

Robin, B. (2006). The Educational Uses of Digital Storytelling. In C. Crawford et al. (Eds.), Proceedings of Society for Information Technology \& Teacher Education International Conference 2006 (pp. 709-716). Chesapeake.

Domingo Calabuig, D., Sentieri Omarrementería, C. (2011). Blended learning in the area of the architectural project: An experience of adjustment to the European space for higher education in the school of architecture of Valencia. In EDULEARN11 Proceedings (pp. 3076-3082). Palma de Mallorca: IATED.

Segrelles, J. D., MOLTÓ, G., Caballer, M. (2015) Remote Computational Labs for Educational Activities via a Cloud Computing Platform. In 2015 Proceedings of the Information Systems Education Conference (ISECON) (pp. 309-321). Orlando. 
Segrelles, J. D., Moltó, G. (2016) Assessment of cloud-based Computational Environments for higher education. In Frontiers in Education Conference (FIE) 2016 IEEE (pp. 1-9). Erie.

Segrelles, J. D., Martínez, A., Castilla, N., Moltó, G. (2017) Virtualized Computational Environments on the cloud to foster group skills through PBL: A case study in architecture. Computers \& Education, 108, 131-144.

de Acedo Lizarraga, M. L. S. (2010). Competencias cognitivas en educación superior (Vol. 25). Narcea Ediciones. 